\title{
ECG Manifestations in Acute Ischaemic Stroke
}

\author{
Dr.Pavithra. $\mathrm{R}^{1}$, Dr. Poornachandra. M. $\mathrm{V}^{2}$, Dr.Vishwanath Krishnamurthy ${ }^{3}$ \\ ${ }^{1}$ Post Graduate Student, Dept. Of General Medicine, Kempegowda Institute of Medical Sciences, Bangalore. \\ ${ }^{2}$. Professor\& HOD, Dept. Of General Medicine, Kempegowda Institute of Medical Sciences, Bangalore \\ 3. Assistant Professor, Dept. Of General Medicine, Kempegowda Institute of Medical Sciences, Bangalore
}

\begin{abstract}
:
Background: Stroke is defined as a rapidly developing symptoms and/or signs with global loss of brain function, lasting for more than $24 \mathrm{hrs}$, or leading to death, with no apparent cause other than vascular origin. A significant number of stroke patients are having co-existent cardiac abnormalities,.

Aim: To find the association between cardiac abnormalities (both symptomatic and asymptomatic) and ischemic stroke, in terms of clinical parameters and ECG.

Method: 50 patients diagnosed to have acute ischemic stroke during the period of December 2011 to September 2013. Data was collected by relevant history, clinical examination, investigations.

Results: The mean age of the patients was in the age group 51-70 years, with a male-female ratio of 7:5. Chest pain (12\%), palpitations(2\%), orthopnoea (6\%) were the main presenting cardiac symptoms. ECG abnormalities noted were T-wave inversion in 38\%, ST segment depression/elevation in 20\%, QTc prolongation in $8 \%$, AF in $6 \%$.

Conclusion: The observations of this study suggest that ECG abnormalities in patients with acute ischaemic stroke are common and cardiac evaluation could have prognostic importance.
\end{abstract}

Key Words: Ischaemic Stroke, ECG.

\section{Introduction}

Cardiac abnormalities in patients with acute stroke were first reported in 4 patients in $1947^{1}$.Abnormalities such as ischemic like ECG changes and/or QT prolongation were present in more than $90 \%$ of unselected patients with ischemic stroke and intracerebral haemorrhage, but the prevalence was much lower after exclusion of patients with pre-existing heart disease. In patients with ischemic stroke and intracerebral haemorrhage, these ECG abnormalities most often represent pre-existing coronary artery disease. They found that the specificity of ECG changes to diagnose acute myocardial infarction is low in the acute phase of stroke. ${ }^{2}$

Numerous studies have shown that mortality from all forms of ischemic cerebrovascular disease is primarily due to coronary artery disease. Thus, there is increasing interest in identifying coronary artery disease in patients with cerebrovascular disease, including those without clinical manifestations of heart disease. ${ }^{3}$

\section{AIM:}

To find the association between cardiac abnormalities[ both symptomatic and asymptomatic] and ischaemic stroke by ECG changes.

\section{Methodology}

The material of the study comprised 50 patients admitted in KIMS Hospital ,Bangalore. Inclusion Criteria:

- Age above 18 years

- Presence of acute ischemic stroke proven by CT/MRI Brain. Exclusion Criteria:

- Age below 18 years

- Patients with known cardiac disease

- Patients with previous cerebrovascular accident

- CKD patients

Method of study: Cross-sectional observational study.

\section{Method of Collection of Data:}

After admission a detailed history regarding the temporal profile of the stroke including risk factors like hypertension, diabetes mellitus, smoking, history of IHD and rheumatic heart disease were obtained. 
Detailed neurological examination including fundoscopy and cardiovascular examination were carried out in all the cases.

The diagnosis of CVA was made on the basis of the following criteria:

- Temporal profile of clinical syndrome

- Clinical examination

- CT/MRI Brain

A 12 lead ECG was done within 24hs of admission.

All patients underwent-

1. Complete blood count

2. Random blood sugar

3. 12 lead ECG

4. CT/MRI Brain

5. Serum creatinine

6. Serum electrolytes

\section{Ecg Criteria:-}

- HR of $<60 /$ min was regarded as bradycardia.

- $\quad$ HR of $>100 /$ min was regarded as tachycardia.

- T-wave was considered abnormal when inversion of $\mathrm{T}$-waves in which it should have been upright i.e. 1,2, V3-V6, may be variable in 3,AVL,V1,V2

- QTc prolongation: The QT interval is measured from the beginning of QRS complex to the end of Twave, the rate corrected QTc is obtained by dividing the actual QT by the square root of the RRinterval(both measured in seconds), QTc is prolonged if it is more than $0.44 \mathrm{~m}$-sec.

- $\quad \mathrm{U}$ - wave is taken as significant when exaggeration of $\mathrm{U}$ - wave voltage was noted when appeared in more than 2-leads when appeared in leads in which it was not normally seen(other than V3-V4)

- $\quad$ RVH: R-waves in right chest leads and R wave may be taller than $\mathrm{S}$ wave in leadV1, persistent $\mathrm{S}$ wave in $\mathrm{V} 5-\mathrm{V} 6$

- $\mathrm{LVH}$

\section{Statistical Analysis:}

- The collective data as well as the proportions and percentages of variables are projected by appropriate charts, tables and graphs. The statistical analysis was done by Chi Square Test.

\section{Results}

A total of 50 patients were analysed in the study.

\begin{tabular}{|c|c|c|c|c|c|c|c|}
\hline & & & & & $\begin{array}{c}\boldsymbol{\chi} \mathbf{2} \\
\text { Value }\end{array}$ & $\begin{array}{c}\text { Distribut } \\
\text { ion of } \\
\text { Patients }\end{array}$ & Age Group (years) \\
\hline & & & & Combined & Female & Male & \\
\hline & $\%$ & $\mathbf{N}$ & $\boldsymbol{\%}$ & $\mathbf{N}$ & $\boldsymbol{\%}$ & $\mathbf{N}$ & $30-50$ \\
\hline $3.06 \mathrm{NS}$ & 24.0 & 12 & 13.3 & 2 & 28.6 & 10 & $51-70$ \\
\hline & 48.0 & 24 & 66.7 & 10 & 40.0 & 14 & $>70$ \\
\hline & 28.0 & 14 & 20.0 & 3 & 31.4 & 11 & Total \\
\hline
\end{tabular}




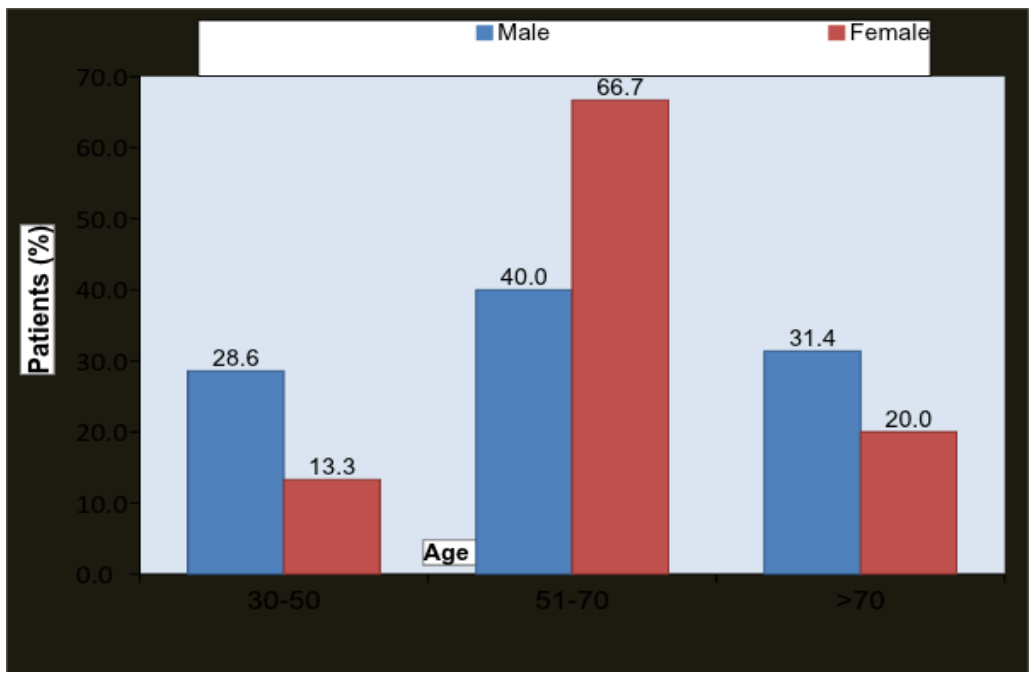

Cardiac symptoms in stroke patients:

\begin{tabular}{|c|c|c|c|c|c|c|c|}
\hline & & & & & $\begin{array}{c}\boldsymbol{\chi 2} \\
\text { Value }\end{array}$ & Response & Symptoms \\
\hline & & & $\begin{array}{c}\text { Combi } \\
\mathbf{n e d} \\
(\mathbf{n = 5 0})\end{array}$ & $\begin{array}{c}\text { Female } \\
(\mathbf{n = 1 5})\end{array}$ & $\begin{array}{c}\text { Male } \\
(\mathbf{n = 3 5})\end{array}$ & \\
\hline & $\mathbf{\%}$ & $\mathbf{N}$ & $\mathbf{\%}$ & $\mathbf{N}$ & $\mathbf{\%}$ & $\mathbf{N}$ & \\
\hline $0.58^{\mathrm{NS}}$ & 12.0 & 6 & 6.7 & 1 & 14.3 & 5 & Chest Pain \\
\hline $1.01^{\mathrm{NS}}$ & 2.0 & 1 & 0.0 & 0 & 2.9 & 1 & Palpitation \\
\hline $2.04^{\mathrm{NS}}$ & 6.0 & 3 & 13.3 & 2 & 2.9 & 1 & Orthopnoea \\
\hline $0.00^{\mathrm{NS}}$ & 0.0 & 0 & 0.0 & 0 & 0.0 & 0 & PND \\
\hline
\end{tabular}

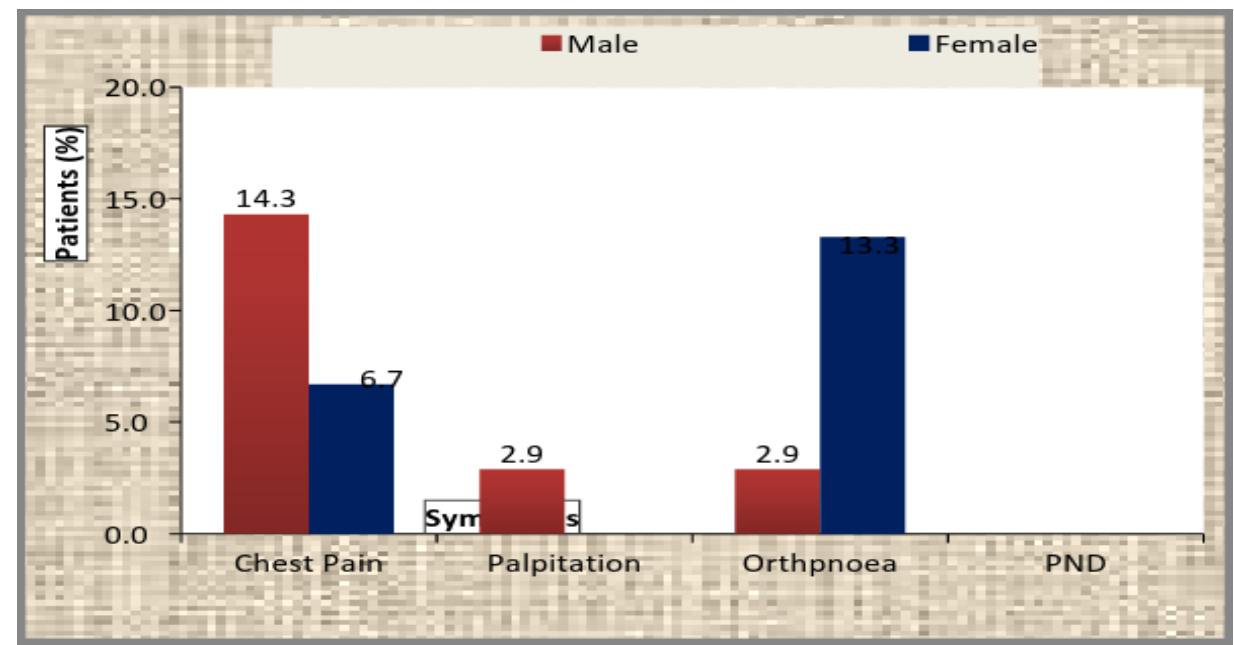

ECG changes in stroke patients:

\begin{tabular}{|c|c|c|c|c|c|c|c|}
\hline & & & & & $\begin{array}{c}\boldsymbol{\chi} \mathbf{2} \\
\text { Value }\end{array}$ & $\begin{array}{c}\text { Respons } \\
\mathbf{e}\end{array}$ & ECG Changes \\
\hline & & & & $\begin{array}{c}\text { Combin } \\
\mathbf{e d} \\
(\mathbf{n = 5 0})\end{array}$ & $\begin{array}{c}\text { Female } \\
(\mathbf{n = 1 5})\end{array}$ & $\begin{array}{c}\text { Male } \\
(\mathbf{n = 3 5})\end{array}$ \\
\hline & $\mathbf{\%}$ & $\mathbf{N}$ & $\mathbf{\%}$ & $\mathbf{N}$ & $\mathbf{\%}$ & $\mathbf{N}$ & OTc Prolongation \\
\hline $4.19^{*}$ & 8.0 & 4 & 20.0 & 3 & 2.9 & 1 & T wave Inversion \\
\hline $4.40^{*}$ & 38.0 & 19 & 60.0 & 9 & 28.6 & 10 & ST Segment \\
\hline $0.06^{\mathrm{NS}}$ & 20.0 & 10 & 26.7 & 4 & 17.1 & 6 & Depression/Elevation \\
\hline $0.00^{\mathrm{NS}}$ & 0.0 & 0 & 0.0 & 0 & 0.0 & 0 & U Wave \\
\hline $2.04^{\mathrm{NS}}$ & 6.0 & 3 & 13.3 & 2 & 2.9 & 1 & AF \\
\hline
\end{tabular}




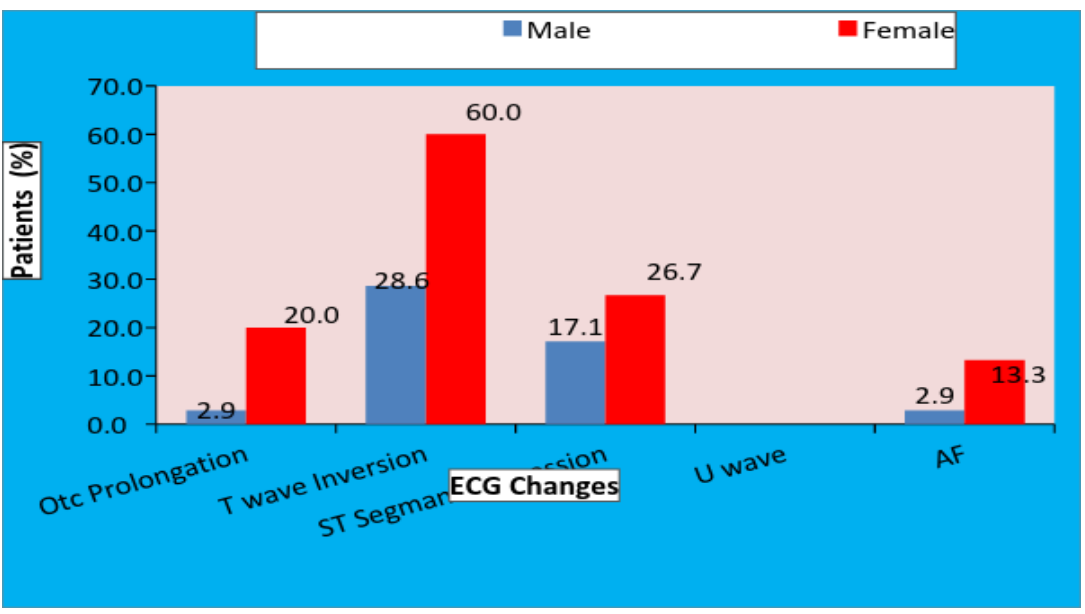

\section{Discussion}

Coronary artery disease and ischemic cerebrovascular disease are leading causes of morbidity and mortality. Coronary artery disease often coexists with symptomatic carotid artery atherosclerosis, transient ischemic attacks, or ischemic stroke. Numerous studies have shown that mortality from all forms of ischemic cerebrovascular disease is primarily due to coronary artery disease. Thus, there is increasing interest in identifying coronary artery disease in patients with cerebrovascular disease, including those without clinical manifestations of heart disease. ECG changes are common in patients with ischemic stroke. In the cross sectional study of 50 patients with acute stroke, presenting cardiac symptoms were chest pain(12\%), followed by orthopnoea, palpitations and PND. The ECG changes were T wave inversion(38\%), ST-T wave changes (20\%), QTc prolongation (8\%), AF in (6\%). Stroke patients had an increased frequency of pathologic Q waves and left ventricular hypertrophy, but these were not new findings at the time of the stroke. The results are consistent with an interaction of underlying hypertensive or atherosclerotic cardiovascular disease, sympathetic hyperactivity, and possibly myocardial necrosis, in producing ECG changes. The study was consistent with the study done by Goldstein et al. ${ }^{4}$

\section{Conclusion}

The study underlies the importance of studying the cardiac abnormalities in patients of acute ischemic stroke which would help in early recognition of the same and in-turn better treatment of patients which helps in decreasing mortality and morbidity of these patients.

\section{References}

[1]. Oppenheimer SM, Hachinski VC. The cardiac consequences of stroke. Neurol Clin 1992; 10:167-76.

[2]. Khechinashvili G, Asplund K. Electrocardiographic changes in patients with acute stroke: a systematic review. Cerebrovascular Dis. 2002;14(2):67-76.

[3]. Koochaki E, Arami M. Eletrocardiogarph Changes in Acute Ischemic Cerebarl Stroke. The Journal of Applied Research. Vol.12,No.1,2012.

[4]. Goldstein DS. The electrocardiogram in stroke:relationship to pathophysiological type and comparison with prior tracings. Stroke,1079; 10:253-259. 